\title{
Uma Reflexão Sobre A Articulação De Teorias Didáticas No Estudo Das Noções De Área E Perímetro
}

A Reflection On The Articulation Of Didactic Theories In The Study Of Area And Perimeter Notions

Cintia Aparecida Bento dos Santos

Universidade Cruzeiro do Sul

\begin{abstract}
Resumo
O presente trabalho tem por objetivo apresentar de forma sucinta uma possível articulação entre teorias didáticas como as de Doaudy (1992), Duval (1993) e a abordagem teórica de Robert (1997), sobre os níveis de conhecimento esperados dos educandos. Considerando que o estudo destes autores são voltados para um trabalho delineado por uma perspectiva que leva em consideração a estrutura cognitiva, apresentamos aspectos da teoria de aprendizagem significativa de Ausubel, pois consideramos que a internalização de conteúdos de forma que possam ser mobilizados em situações futuras quando a noção em jogo não é explícita só se faz possível se os métodos de ensino se estruturam em uma aprendizagem significativa. Dessa forma, faremos uma breve exposição das teorias escolhidas na tentativa de mostrar como este estudo pode auxiliar professores no momento de suas escolhas, assim como podem compreender melhor as dificuldades e os diferentes níveis que se encontram os alunos, o que pode lhes permitir construir sequiências didáticas mais adequadas e levar ainda em consideração a importância não somente do domínio matemático do conteúdo, mas também a relevância do domínio didático das noções a serem tratadas em sala de aula. Ao final destas reflexões podemos compreender melhor o papel até mesmo da formação inicial e continuada de professores, perspectiva esta que abordaremos segundo Shulman (2005).
\end{abstract}

Palavras-chave: Níveis de conhecimento. Aprendizagem significativa. Área e perímetro. Registros de representação semiótica. Mudanças de quadro.

\begin{abstract}
The present work aims to present a succinct articulation between didactic theories such as those of Doaudy (1992), Duval (1993) and Robert's theoretical approach (1997) on the levels of knowledge expected of students. Considering that the study of these authors are geared towards a work outlined by a perspective that takes into account the cognitive structure, we present aspects of Ausubel's meaningful learning theory, as we consider that the internalization of contents so that they can be mobilized in future situations when the notion at stake is not explicit only becomes possible if the teaching methods are structured in meaningful learning. Thus, we will give a brief exposition of the chosen theories in an attempt to show how this study can help teachers at the time of their choices, as well as to better understand the difficulties and the different levels that are the students, which can allow them to construct sequences and also take into account the importance not only of the mathematical domain of content but also the relevance of the didactic domain of the notions to be treated in the classroom. At the end of these reflections we can better understand the role of even initial and continuing teacher training, a perspective that we will address according to Shulman (2005).
\end{abstract}

Keywords: Levels of knowledge. Meaningful learning. Area and perimeter. Records of semiotic representation. Frame changes. 


\section{Introdução}

As noções de área e perímetro aos olhos de professores de matemática, muitas vezes pode parecer simples e o fato dos educandos conhecerem as fórmulas relativas ao cálculo de área dos polígonos regulares o suficiente para que estes mobilizem estas noções em situações futuras onde a noção em jogo não é explícita. Porém devemos levar em consideração que esta mobilização de conteúdos não é algo tão simples assim para os alunos e que nem sempre o insucesso na resolução de determinadas tarefas está apenas associada a difículdades relacionadas com as competências leitoras (Santos, 2008).

Este artigo apresenta uma abordagem teórica sobre teorias didáticas com o objetivo de iniciar uma reflexão sobre a aprendizagem das noções de área e perímetro que são tratadas nos anos finais do Ensino Fundamental, uma vez que, somente a aprendizagem voltada à aplicação técnica de fórmulas parece não estar dando conta de cumprir seu papel com efetiva eficiência no processo ensino-aprendizagem. Para isso apresentaremos alguns aspectos de teorias que acreditamos serem de grande valia para esta reflexão, como a abordagem teórica de Robert ${ }^{1}$ (1997), sobre os níveis de conhecimento esperados dos educandos, pretendemos ainda, ao abordar os estudos de Robert (1997) fazer uma articulação entre as teorias de Douady² (1992), sobre mudanças de quadro ${ }^{3}$ e os estudos de Duval $^{4}$ (1993) sobre as representações semióticas ${ }^{5}$, que irão configurar como ferramentas para que professores possam entender como se dá as passagens dos níveis, uma vez que estes não se fazem de forma hierárquica. Considerando ainda a teoria de aprendizagem significativa de Ausubel (1980), será possível evidenciar o prejuízo de uma aprendizagem mecânica, uma vez que esta teoria considera que para uma aprendizagem ser significativa é preciso que se construam materiais potencialmente significativos. Contudo deve-se lembrar que a teoria da aprendizagem significativa considera que é preciso que se construam materiais potencialmente significativos, mas ela não indica nenhuma forma de análise que auxilie na construção desse material. Da mesma forma que Robert (1997), não nos fornece "pistas" de como ocorrem a passagem dos níveis, ou seja, que escolhas didáticas o

\footnotetext{
${ }^{1}$ Aline Robert: Pesquisadora francesa.

${ }^{2}$ Régine Douady: Pesquisadora francesa

${ }^{3}$ Quadro ou domínio: Constituído de objetos de um ramo das matemáticas, das relações entre os objetos, de suas formulações eventualmente diversas e das imagens mentais associadas a esses objetos e essas relações. Essas imagens têm um papel essencial e funcionam como ferramentas dos objetos do quadro. Dois quadros podem conter os mesmos objetos e diferir pelas imagens mentais e problemáticas desenvolvidas. (DOUADY,1992, p.135)

${ }^{4}$ Raymond Duval: Filósofo e psicólogo francês.

${ }^{5}$ Registros de representação semiótica: Representações matemáticas referentes a um sistema de significação. (DUVAL, 1993)
} 
professor pode fazer afim de possibilitar o êxito dos educandos quando ocorre a necessidade de transposição destes níveis.

Com base nestas considerações serão apresentados alguns aspectos destas teorias e algumas possíveis articulações que vislumbram um tratamento didático diferenciado para as noções aqui abordadas.

\section{Alguns Aspectos Da Teoria De Aprendizagem Significativa Segundo Ausubel.}

Para Ausubel (1980) uma aprendizagem automática é aquela que se faz por decoração, ou seja, de forma mecânica; enquanto que a aprendizagem significativa leva em consideração os conhecimentos prévios dos educandos no momento da introdução de novos conceitos. Dessa forma o autor afirma que:

[...] a aprendizagem significativa ocorre quando a tarefa de aprendizagem implica relacionar, de forma não arbitrária e substantiva (não literal), uma nova informação a outras com as quais o aluno já esteja familiarizado, e quando o aluno adota uma estratégia correspondente para assim proceder. A aprendizagem automática, por sua vez, ocorre se a tarefa consistir de associações puramente arbitrárias, como na associação de pares, quebracabeça, labirinto, ou aprendizagem de séries e quando falta ao aluno o conhecimento prévio relevante necessário para tornar a tarefa potencialmente significativa, e também (independentemente do potencial significativo contido na tarefa) se o aluno adota uma estratégia apenas para internalizá-la de uma forma arbitrária, literal (por exemplo, como uma série arbitrária de palavras). (AUSUBEL, 1980, p.23)

Deve-se lembrar que a aprendizagem significativa não depende apenas do papel desempenhado pelo professor. É necessário que o aluno assuma seu papel e participe como ator neste jogo. Segundo AUSUBEL (1980):

A aprendizagem significativa pressupõe que o aluno manifeste uma disposição para a aprendizagem significativa - ou seja, uma disposição para relacionar, de forma não arbitrária e substantiva, o novo material a sua estrutura cognitiva $[\ldots]$ (p.34)

É importante salientar que a cultura matemática relacionada ao estudo das noções de área e perímetro tem sido fundamentada no uso excessivo de fórmulas. Este procedimento matemático pode ser de rápida aquisição quanto a manipulação de soluções e sucesso escolar para os educandos na resolução de determinadas tarefas, porém sem significado algum e de pouca valia. A constatação destas considerações pode ser observada no texto abaixo:

[...] os alunos desenvolvem uma disposição para a aprendizagem automática, se passam a sentir-se excessivamente pressionados para demonstrar desembaraço ou omitir suas dificuldades pessoais em compreender genuinamente um determinado assunto, em lugar de admiti-las e 
gradualmente vencê-las. Sob estas circunstâncias, parece que criar uma impressão espúria de compreensão fácil, através da memorização automatizada de algumas sentenças ou termos-chaves, torna-se mais fácil e mais importante do que tentar compreender o que eles significam. Os professores esquecem frequentemente que os alunos tornam-se facilmente adeptos da utilização de termos abstratos com um emprego aparentemente adequado - quando é preciso - muito embora inexista virtualmente uma compreensão dos conceitos subjacentes. (AUSUBEL, 1980, p.36)

Ainda com referência ao texto acima, podemos afirmar que:

[...] para que a aprendizagem significativa ocorra de fato, não é suficiente que as novas informações sejam simplesmente relacionadas (...); é também necessário que o conteúdo ideacional relevante esteja disponível na estrutura cognitiva de um determinado aluno. (AUSUBEL, 1980, p.37)

Contudo cabe lembra que a aprendizagem mecânica não deve ser abolida, pois esta tem seu papel na aprendizagem, mas é preciso trabalhá-la de forma articulada, levando-se em conta os conhecimentos prévios dos alunos uma vez que esses conhecimentos são as ferramentas explicitas do trabalho matemático em jogo no desenvolvimento de determinadas tarefas.

\section{Síntese Da Abordagem Teórica De Robert Sobre Os Níveis De Conhecimento Esperados} Dos Educandos.

Segundo abordagem teórica de Robert (1997) os níveis de conhecimento esperados dos educandos são três e se dividem em: técnico, mobilizável e disponível.

O nível técnico é aquele que corresponde a resolução de uma tarefa em que sua solução está associada a utilização concreta de uma ferramenta, como por exemplo, a aplicação de uma fórmula ou um teorema. Dessa forma a noção em jogo está explicita e não são necessárias adaptações ou mobilização de conteúdos.

Para o nível mobilizável já existe uma justaposição de saberes de um determinado domínio, ou seja, corresponde à resolução de uma tarefa pelo aluno em que apesar da noção em jogo estar explícita é necessário uma pequena adaptação, em que o aluno é obrigado a mobilizar conhecimentos prévios para resolução da tarefa. Nesta etapa a resolução da tarefa não se encontra associada mais apenas à pura aplicação de uma fórmula ou teorema. Neste nível aceitase ainda uma indicação ou ajuda do professor para que o aluno resolva a tarefa proposta.

Segundo Robert o nível disponível é aquele em que o aluno deve resolver a tarefa proposta sem nenhuma indicação ou ajuda do professor, neste nível é necessário recorrer a conhecimentos anteriores, às vezes ainda é preciso articular conhecimentos em diferentes quadros ou até no mesmo quadro, porém com diferentes noções em jogo (ROBERT, 1997). 
Este nível representa tarefas que significam um desafio, uma vez que, o aluno deve organizar seus conhecimentos anteriores de forma a planejar a solução. Dessa forma podemos perceber que para resolução de tarefas neste nível exigem que o aluno resgate conhecimentos anteriores sobre as noções em jogo necessárias para resolução da tarefa. Assim, a noção em jogo não é explícita e necessita de uma transposição de métodos, onde se faz necessário articular conteúdos, ou seja, é necessária certa flexibilidade cognitiva.

A flexibilidade cognitiva aqui tratada pode ser entendida como: a disposição mental de articular diversos domínios que são internalizados a partir de uma aprendizagem significativa, transferindo conhecimentos aprendidos anteriormente para resolução de novas situações propostas, ou seja, é um estado cognitivo onde o aluno age com autonomia e está fundamentada na TFC (Teoria de Flexibilidade Cognitiva) de Spiro (1988), conforme se esclarece abaixo:

A Teoria da Flexibilidade Cognitiva (TFC) foi proposta na década de 80 por Rand Spiro e colaboradores. É, segundo os seus autores, uma teoria de aprendizagem, da representação e do ensino (Spiro et al., 1988). O desenvolvimento da flexibilidade cognitiva requer múltiplas representações do conhecimento, favorecendo estas a transferência de conhecimento para novas situações. A teoria encontra-se orientada para a aquisição de conhecimento em níveis avançados. Não se pretende, deste modo, a mera memorização de um assunto. Pretende-se, isso sim, que o sujeito, quando deparado com uma situação detentora de novidade, seja capaz de reestruturar as suas estruturas de conhecimento por forma a solucionar um dado problema, isto é, adquira a flexibilidade cognitiva necessária para a transferência de conhecimento. (PEDRO E MOREIRA, 2000, p.31)

Porém esta flexibilidade cognitiva necessária ao aluno, a nosso ver, depende não apenas do que o professor efetivamente ensina em sala de aula, mas da forma como ensina, ou seja, depende intrinsecamente dos conhecimentos didáticos do conteúdo pelo professor, esta nos parece uma característica fundamental quando se deseja um trabalho diferenciado em Educação Matemática.

\section{Síntese De Alguns Aspectos Da Teoria De Duval.}

Considerando que o grau de dificuldade de uma tarefa proposta ao educando deva levar em conta os símbolos matemáticos ali envolvidos e que caminhos possibilitarão sua resolução, deve-se observar os diferentes pontos de vista, uma vez que para uma questão pode-se existir diversas formas de resolução dependendo da leitura do aluno, ou ainda, ele pode se apropriar de uma ferramenta que não tenha relação com a noção em jogo naquele momento. O que se pretende dizer é que no campo da educação matemática a flexibilidade cognitiva depende de inúmeros fatores e que estes estão associados não somente "ao que o professor ensina", mas 
“como o professor ensina".

Imaginar que determinados educandos não apresentam êxito na resolução de tarefas quando a noção em jogo envolve certos domínios matemáticos devido a dificuldade de interpretação de texto, parece neste contexto não ser a colocação mais correta em vista da gravidade do problema (Santos, 2008). O fato é que a matemática apresenta sua própria linguagem, o que muitas vezes torna inacessível ao aluno determinadas tarefas.

Faz-se necessário entender melhor o papel desempenhado pela linguagem matemática e suas representações, considerando este o ponto estratégico para a aprendizagem em matemática.

Existe uma palavra ao mesmo tempo importante e secundária em matemática: é a palavra "representação". Ela é muito freqüentemente empregada sob sua forma verbal "representar" uma escrita, uma notação, um símbolo representando um objeto matemático: um número, uma função, um vetor,... Até mesmo os traçados e as figuras representando os objetos matemáticos: um segmento, um ponto, um círculo... Isso quer dizer que os objetos matemáticos não devem jamais ser confundidos com a representação que lhes é feita. Com efeito, toda confusão ocasiona, em maior ou menor termo, uma perda de compreensão e os conhecimentos adquiridos tornam-se rapidamente inutilizáveis fora de seu contexto de aprendizado: seja por não chamamento, seja porque existem como representações "inertes" não sugerindo nenhum tratamento. A distinção entre um objeto e sua representação é então um ponto estratégico para a compreensão da matemática. (DUVAL, 1993, p.37)

Pode-se observar que segundo a citação acima a distinção entre objetos e suas representações dentro dos domínios matemáticos é um forte fator que pode influenciar a aprendizagem, quando relaciona-se esta idéia as noções de área e perímetro percebe-se a importância destas considerações, uma vez que o contexto destas noções envolve representações, ainda que mentais, para solução de tarefas.

Dessa forma, entendemos que "as representações semióticas têm um papel fundamental na atividade matemática" (DUVAL, 1993, p.38), assim descreve-se definição de DUVAL (1993) para representações semióticas:

As representações semióticas são produções constituídas pelo emprego de signos [sinais] pertencentes a um sistema de representação que têm suas dificuldades próprias de significância e de funcionamento. Uma figura, um enunciado em língua natural, uma fórmula algébrica, um gráfico, são representações semióticas que salientam sistemas semióticos diferentes Consideram-se geralmente as representações semióticas como um simples meio de exteriorização das representações mentais para fins de comunicação, ou seja, para deixá-las visíveis ou acessíveis a outrem. (DUVAL, 1993, p.39)

Duval (2003) define os diferentes tipos de representações semióticas que podem ser mobilizadas na articulação dos domínios matemáticos em quatro tipos, da seguinte forma: a 
língua natural (associações verbais) e os sistemas de escrita (registro numérico, registro simbólico e registro algébrico), estes dois estão relacionados a representação discursiva; e dois associados a representação não-discursiva que são o registro figural ( por exemplo figuras geométricas planas) e o registro gráfico ( por exemplo o plano cartesiano com o sistema de coordenadas). Cabe ressaltar que um registro pode dar origem à passagem para outro registro (DUVAL, 2004).

Assim, podemos entender que: A originalidade da atividade matemática está na mobilização simultânea de ao menos dois registros de representação ao mesmo tempo, ou na possibilidade de trocar a todo momento de registro de representação (DUVAL, 2003, p.14).

Contudo cabe explicitar que existem dois tipos diferentes de mudanças de registros e são elas: os tratamentos e as conversões. Os tratamentos representam transformação de uma representação em outra, porém permanecendo no mesmo registro. As conversões representam a transformação de uma representação em outra, porém mudando de registro.

Podemos então afirmar que:

A compreensão (integral) de um conteúdo conceitual repousa sobre a coordenação de ao mesmo dois registros de dois registros de representação e esta coordenação manifesta-se pela rapidez e espontaneidade da atividade cognitiva de conversão. (DUVAL ${ }^{6}$ apud MORETTI, 2002,p.349)

Com base nestas considerações podemos entender a necessidade de um trabalho articulado com os diferentes registros de representação, uma vez que, ao coordenar diferentes registros sobre um mesmo objeto do saber matemático o educando evidencia sua potencialidade em relação a flexibilidade cognitiva.

\section{Síntese De Alguns Aspectos Da Teoria De Douady}

Douady, considera que as noções de área e perímetro devam ser trabalhadas enquanto objeto (DOUADY, 1992, p.134) do saber matemático, funcionando como ferramenta explícita quando surge a necessidade de trabalhar outros domínios em que a questão em jogo configura de forma implícita.

Cabe lembrar que Douady define objeto como:

[...] objeto cultural tendo seu lugar em um edifício mais amplo que é o saber das matemáticas, num dado momento, reconhecido socialmente. O objeto é matematicamente definido, independentemente de sua utilização. O status de objeto permite a capitalização do saber e, portanto, a extensão do corpo de

\footnotetext{
${ }^{6}$ Duval, R. Registres de representation sémiotique e fonctionnement cognitif da la penseé. Annales de didactique et de sciences cognitives, v5.1993.
} 
conhecimentos. Ele permite também o reinvestimento em novos contextos, eventualmente, muito distintos do contexto original. (Douady, 1992, p.134)

Régine Douady propõe a mudança ou jogo de quadros como meio de fazer evoluir as concepções dos alunos em Matemática (BALACHEFF, 2002). Em seu primeiro artigo onde apresentou seu trabalho de tese em Recherches em didactique des mathématiques, Régine Douady utiliza a seguinte definição de quadro em que se observa uma dimensão cognitiva:

Um quadro é constituído de objetos de um ramo da Matemática, de relações entre esses objetos, de suas formulações eventualmente diversas e de imagens mentais associadas a esses objetos e essas relações. Essas imagens têm um papel essencial no funcionamento dos objetos do quadro como ferramentas. Dois quadros podem comportar os mesmos objetos e diferir pelas imagens mentais e a problemática desenvolvida. (Douady, 1986, p. 11)

Desta forma o domínio matemático é constituído de vários quadros, que são definidos por Douady da seguinte forma: Quadro geométrico (Constituído por superfícies planas, como polígonos regulares e irregulares); Quadro numérico (Constituído por medidas das superfíciesexpressas por meio de números positivos que podem se inteiros, fracionários ou irracionais); Quadro das grandezas (Contexto próprio da noção de área, incluindo a equivalência formada por superfícies de mesma área. É um processo de comparação das grandezas não necessariamente numérico).

Com nossa prática percebemos que muitas vezes, determinadas tarefas, em geral aquelas associadas ao nível disponível, tem sua resolução no quadro algébrico, em que os educandos devem disponibilizar, por exemplo, conceitos relativos a resolução de equações polinomiais de 20 grau. A nosso ver aqui reside a grande problemática do baixo desempenho de alguns educandos na resolução destas tarefas, uma vez que embora pareça à primeira vista um caminho muito simples, não é, pois estas articulações solicitadas dos alunos não são espontâneas e estão associadas aos meios de aprendizagem. Dessa forma podemos concluir que por mais que um professor domine seu conteúdo, se desconhecer determinados conceitos da didática da matemática, provavelmente em sala de aula não terá o sucesso esperado.

Uma reflexão importante é que o aluno deve não apenas conhecer estes quadros, mas também aprender com autonomia a ir de um quadro a outro e nem sempre isto acontece no cotidiano escolar. Nesse sentido, as situações didáticas devem ser trabalhadas de forma que possibilitem ao educando as articulações necessárias para resolver as tarefas propostas que exigem mudança de quadros ou de registros de representação. 


\section{Alguns Aspectos De Articulação Entre As Teorias Apresentadas}

Para os conceitos de perímetro e área, escolhidos como conteúdos matemáticos abordados neste artigo, pretendemos encontrar novas possibilidades de tratamento didático permitindo meios de reflexão que possam auxiliar na construção de metodologias que permitam aos professores conduzir estudantes a utilizarem seus conhecimentos técnicos em tarefas em que os níveis de conhecimento exigido são o mobilizável e o disponível, de forma ainda a aproveitar o conhecimento já armazenado em sua estrutura cognitiva, ou seja, seu conhecimento prévio.

Consideramos inclusive que a abordagem teórica proposta por Robert (1997) conduz a análises que exigem que se considerem, por exemplo, os diferentes quadros ou domínios de Douady (1992), que podem ser articulados, aos diferentes registros de representação semiótica (DUVAL, 1993) que estão em jogo no trabalho que se pretende desenvolver, com base nestas considerações podemos ainda vislumbrar as possibilidades de conversão destes registros, conforme a abordagem de Duval (1993), como uma forma de auxiliar professores no desenvolvimento de sua própria autonomia ao elaborar metodologias didáticas.

Ao apresentarmos as teorias de Ausubel, Douady, Duval e a abordagem teórica de Robert, pretendemos introduzir elementos que auxiliem na reflexão sobre diferentes tarefas e metodologias, que podem ser desenvolvidas no ensino de áreas e perímetros, a fim de melhorar o processo de ensino aprendizagem, possibilitando a articulação de quadros ou domínios e escolhendo a representação adequada dos objetos relacionados à noção em jogo por meio de diferentes registros de representação semiótica (DUVAL, 1993) e ser capaz de converter esses registros quando a tarefa exigir, ou seja, desenvolver a capacidade de um trabalho flexível que permite a articulação dos três níveis.

Com base na apresentação da abordagem teórica de Robert, conforme descrita em item anterior, cabe ressaltar que os níveis de conhecimento esperados dos educandos, podem ser entendidos melhor quando se faz um eixo de ligação entre mudanças de quadro e registros de representação semiótica. O ideal é que uma aprendizagem esteja associada a vários quadros, em que o aluno deve conhecer o nível técnico que indiscutivelmente também tem sua importância, mas que, além disso, tenha direito ao acesso de construção de conhecimento para que possa dispor de recursos em situações futuras e isso não tem sua importância apenas no ambiente escolar, mas sim em sua vida diária.

Enquanto Duval nos fornece um referencial estruturado no funcionamento cognitivo, 
aqui pode-se vislumbrar que quando o educando consegue mobilizar os diferentes registros de representação semiótica tem-se então uma aprendizagem significativa e por conseqüência a autonomia do educando solucionando tarefas associadas ao nível mobilizável e disponível.

É importante observarmos que, para determinadas noções, é necessário que a aprendizagem se faça também de uma forma técnica, porém não mecanizada, pois a aprendizagem automática não possibilita a relação entre novos significados (AUSUBEL, 1980), o que mostra a importância do nível técnico que deve ser trabalhado de forma articulada com os níveis mobilizável e disponível propostos por ROBERT (1997) que podem ser entendidos como as interações sucessivas que ocorrem na aprendizagem significativa conforme MOREIRA E MASINI (2001): “À medida que a aprendizagem significativa ocorre, conceitos são desenvolvidos, elaborados e diferenciados em decorrência de sucessivas interações”. (p.29)

Ao considerarmos que a idéia central da Teoria de Ausubel é a de que o fator isolado mais importante influenciando a aprendizagem é aquilo que o aprendiz já sabe (MOREIRA E MASINI, 2001, p.17), o que de certa forma está associado aos níveis de conhecimento esperado dos alunos, pois é importante conhecer qual o nível que pode ser considerado esse conhecimento prévio.

Com base nas referências teóricas podemos entender a necessidade de um novo papel para o ensino de determinadas noções matemáticas, para que o educando possa trabalhar com autonomia os saberes internalizados quando a questão em jogo necessita de mobilização de conteúdos, ou seja, quando a tarefa solicitada requer o nível mobilizável ou disponível.

Porém observamos que em sua abordagem teórica Robert não nos fornece pistas metodológicas de como o professor deve conduzir o educando a passagem um nível a outro, enquanto Ausubel também não nos remete pistas de como construir materiais potencialmente significativos, em face destas constatações pode-se vislumbrar através das mudanças de quadro e das representações semióticas, ferramentas que podem auxiliar a aprendizagem.

É importante observar também que "o ensino habitual está centrado no funcionamento do quadro algébrico" (ARTIGUE, 1996, p.200), dessa forma outras noções ou quadros matemáticos ficam deixados de lado, não exercendo o papel que deveriam no processo ensinoaprendizagem. Porém é preciso que o aluno tenha o direito à ampliação de seus conhecimentos para que possa agir de forma plena em situações futuras, não somente relacionadas ao ambiente escolar, ou seja, é necessário institucionalizar ${ }^{7}$ os conhecimentos nos diferentes quadros que

\footnotetext{
${ }^{7}$ Segundo Brousseau (1996), o objeto da institucionalização constitui o duplo reconhecimento entre a consideração oficial do objeto do ensino por parte do aluno, e da aprendizagem do aluno por parte do professor, sendo um fenômeno social muito importante e uma fase essencial do processo didático.
} 
ele permite sua utilização.

Dessa forma ao tentar articular, alguns aspectos das teorias aqui apresentadas, podemos entender melhor as situações relacionadas acima. Considerando que o sistema educacional se baseia muitas vezes em uma aprendizagem automática, em que se privilegia o nível técnico, porém as avaliações institucionais exigem a mobilização de conteúdos onde a maioria das tarefas solicitadas se encontra no nível mobilizável e disponível. Devemos levar em consideração ainda que a interpretação e reprodução dos diferentes tipos de representação e a necessidade de eventuais mudanças de quadro não são situações tão simples como muitas vezes parecem perante os alunos.

Porém esta flexibilidade cognitiva esperada dos educandos não se constrói sem uma aprendizagem significativa, pois “o período de fixação daquilo que é aprendido mecanicamente é relativamente breve “ (AUSUBEL, 1980, p.122). Dessa forma para exigir a mobilização de conteúdos é necessário que se tenha trabalhado de forma a fixar na estrutura cognitiva do educando uma articulação entre os conhecimentos prévios e as novas noções em jogo a serem internalizadas. Caso isso não ocorra se torna inviável a articulação de conteúdos pelos educandos e o desenvolvimento efetivo de tal flexibilidade cognitiva esperada.

\section{Considerações Finais}

Partindo destas considerações verificamos que a aprendizagem deve estar associada à articulação dos três níveis, ou seja, o aluno deve conhecer nível técnico que é a ferramenta explícita para a solução das tarefas em que a noção deve ser utilizada, mas para poder aplicar estas técnicas seja de forma mobilizável ou disponível é preciso que o novo conhecimento seja trabalhado nos três níveis para que o aluno possa buscar situações de referência que poderão auxiliar no reconhecimento da noção que deve ser utilizada, assim como da representação mais adequada para o desenvolvimento da tarefa que lhe é proposta tanto na vida escolar como na profissional.

Segundo Douady (1992), uma ferramenta explícita representa a utilização de um objeto do saber matemático de forma intencional para resolver um problema. No caso aqui abordado pode-se tomar o seguinte exemplo: Dada a medida do lado de um quadrado é solicitado que o aluno calcule sua área, no caso ele deve aplicar a fórmula, esta representa a ferramenta explícita.

Cabe ressalva que para os educandos mobilizarem estes níveis de conhecimento se faz necessário o domínio sobre as diferentes representações matemáticas, o que constitui uma 
linguagem própria deste domínio e essa aquisição é a nosso ver conseqüência de uma aprendizagem significativa. Estas ferramentas matemáticas típicas da flexibilidade cognitiva não são tão simples assim de serem tratadas e dependem do que na visão de Shulman (2005) constitui uma das três vertentes no conhecimento do professor, quando se refere ao conhecimento da disciplina para ensiná-la, no caso o conhecimento didático do conteúdo da disciplina.

Para Shulman (2005), o conhecimento didático do conteúdo representa uma mistura entre conteúdo e didática para se chegar a uma compreensão de como determinados temas e problemas se organizam, se representam e se adaptam aos diversos interesses e capacidades do educando, se articulando para sua aprendizagem. O conhecimento didático do conteúdo é a categoria que com maior probabilidade permite distinguir entre a compreensão do especialista em uma área do saber e do pedagogo.

Assim nos parece evidente que quando se deseja que os educandos desenvolvam tarefas que não dependem apenas do nível técnico se faz necessária a flexibilidade cognitiva e para que esta se desenvolva é preciso que o aluno tenha tido um ambiente de aprendizagem dentro de uma estrutura que leve em consideração a aprendizagem significativa, a fim de guardar conceitos que possam ser utilizados em situações futuras. Aqui entra a importância do conhecimento dos diferentes registros de representação semiótica e das mudanças de quadro, apresentando claramente a linguagem própria existente na matemática.

Porém cabe lembrar que esta estrutura cognitiva só pode ser desenvolvida pelo aluno a partir do momento em que o professor tenha pré-disposição ao conhecimento didático das noções a serem trabalhadas em sala de aula, o que exige um trabalho diferenciado. Assim podemos perceber que o conhecimento do conteúdo pelo professor não é fator suficiente para uma aprendizagem quando se visa a flexibilidade cognitiva.

Um outro fator que nos parece relevante é o fato de que a abordagem teórica de Robert (1997) contribui de forma efetiva ao apresentar a distinção entre os níveis de conhecimento esperados dos educandos e estes configurarem como ferramenta que pode indicar a dificuldade encontrada por alguns alunos em resolver determinadas tarefas matemáticas, porém em nenhum momento ela nos fornece pistas, como foi citado inicialmente, de como o professor pode ajudar o educando a transpor estes níveis. Da mesma forma como Ausubel (1980) não nos fornece indicações de como se podem construir materiais potencialmente significativos. Assim quando articulamos as teorias de Duval (1993) e Doaudy (1992), podemos entender que a passagem dos níveis está relacionada a mudanças de quadro e aos tipos de registros de representação 
utilizados de forma implícita ou explícita em uma determinada tarefa, observamos que se houver um trabalho diferenciado que leve em consideração estas linguagens próprias da matemática podemos entender melhor as dificulades encontradas pelos educandos e até mesmo estratégias de ajudá-los a alcançar êxito na resolução destas tarefas.

Cabe ressalva que todos esforços realizados em relação ao estudo das teorias didáticas podem muitas vezes serem inúteis, quando não se considera a formação inicial e continuada de professores, para que estes não conheçam apenas os conteúdos a ensinar e sim que façam escolhas relacionadas a como ensinar, observando o papel fundamental da didática da matemática na institucionalização dos saberes.

\section{Referências}

ARTIGUE, M. Engenharia didáctica. In: Brun, Jean (org). Didáctica das matemáticas. Instituto Piaget, Lisboa. Delachaux et Niestlé, S.A., 1996. Trad. Maria José Figueiredo. Coleção Horizontes Pedagógicos, p.193-217.

AUSUBEL, David P .et al. Psicologia Educacional. Segunda Edição. Tradução Eva Nick e outros. Rio de Janeiro-RJ. Editora Interamericana Ltda, 1980.

BALACHEFF, NICOLAS. Quadro, registro e concepção: considerações sobre as relações entre três conceitos chaves da didática. Lês cahier du laboratoire Leibniz, n0 58, setembro de 2002. Disponível em: www.leibniz.imag.fr/LesCahiers. Acesso em: 04/12/2007.

BROUSSEAU, G. Os diferentes papéis do professor. In: PARRA, C.; SAIZ, I. et.al. Didática da Matemática: reflexões psicopedagógicas. Trad. Juan Acuña Llorens. Porto Alegre: Artes Médicas,1996. p.48-72.

DOUADY, R. Des apports de la didactique des mathématiques à l'enseignement. Repères, IREM, n.6, Topiques Editins, janvier, 1992.

DUVAL, Raymond. Registros de representações semióticas e funcionamento cognitivo da compreensão em matemática In: Machado, S.D.A (org.). Aprendizagem em matemática: registros de representação semiótica. Campinas, SP: Papirus, 2003. p. 11-33.

. Registres de représentation sémiotique et fonctionnement cognitif de la pensée. Annales de Didactiques et de Sciences Cognitives 5. IREM de Strasbourg, p.37-65. 1993.

MORETTI, M.T. O papel dos registros de representação da aprendizagem de matemática.

Contrapontos, ano 2- n.6. Itajaí, set./dez.2002, p.343-362.

MOREIRA, M.A; MASINI, E.F.S. Aprendizagem Significativa: a teoria de David Ausubel. São Paulo : Centauro,2001.

PEDRO, L.F.; MOREIRA, A. Os hipertextos de flexibilidade cognitiva e a planificação de conteúdos didácticos: um estudo com (futuros) professores de línguas. Revista de Enseñanza y Tecnologia. Laboratório de Courseware Didáctico Departamento de Didáctica e Tecnologia Educativa Campus de SantiagoUniversidade de Aveiro, Portugal. Septiembre - Diciembre, 2000, p.29-35. Disponível em: http://redalyc.uaemex.mx/redalyc/pdf/374/37413108.pdf. Acesso em jan/2015. 
ROBERT, Aline. Quelques outils d'analyse épistemologique et didactique de connaissances mathématiques à enseigner au lycée et à l'université. Actes de la IX école d'étè de didactique des mathématiques. Houlgate. França, 1997.

SANTOS, C. A. B. Formação de professores de matemática: contribuições de teorias didáticas no estudo das noções de área e perímetro. 2008. 156 f. Dissertação (Mestrado em Ensino de Ciências e Matemática) - Universidade Cruzeiro do Sul, São Paulo, 2008.

SHULMAN, L.S. Conocimiento y enseñanza: fundamentos de la nueva reforma. Revista de currículum y formacíon del professorado. 9,2 (2005). Disponível em:

http://www.ugr.es/local/recfpro/Rev92ART1.pdf . Acesso em: abril/2008.

SPIRO, R.; COULSON, R.; FELTOVICH, P.; ANDERSON, D. Cognitive Flexibility Theory: advanced knowledge acquisition in ill-structured domains. In Patel, V. (ed.) Tenth Annual Conference of the Cognitive Science Society, Hillsdale, NJ: Lawrence Erlbaum. 1988. 